\title{
Trend Analysis of Hydro-meteorological variables in the coastal area of Lagos using Mann-Kendall trend and Standard Anomaly Index methods
}

\author{
*11SALAMI, AW; ${ }^{1}$ IKPEE OD; ${ }^{2}$ IBITOYE, AB; ${ }^{3}$ ORITOLA, SF \\ ${ }^{1}$ Department of Water Resources \& Environmental Engineering, University of Ilorin, Ilorin \\ ${ }^{2}$ Department of Civil and Environmental Engineering, Kwara State University, Malete ${ }^{3}$ Department of Civil Engineering, Federal \\ University of Technology, Minna \\ Corresponding author's e-mail: awsalami2009@gmail.com
}

\begin{abstract}
This paper presents the application of Mann-Kendall trend test and Standard Anomaly index onhydro-meteorological variables in the coastal area of Lagos state in order to determine the nature of trend and level of significance. The hydro-meteorological data such as air temperature, relative humidity, wind speed, rainfall and sea level rise were obtained from Nigeria meteorological agency (NIMET) Oshodi, Lagos. Variables such as rainfall, relative humidity, wind speed and sea level rise exhibited positive Kendall's (S) values indicate upward trend and imply an increase of the parameters over time. However, temperature showed negative Kendall's (S) which indicates downward trend and implies decrease over time. Sea level rise, rainfall, relative humidity and wind speed has mean statistics Zs of 3.9855, 1.9668, 3.0895 and 2.2553 respectively which are more than 1.96 (test statistics for a significant level of $5 \%$ that is $\left(Z_{0.025}=1.96\right)$, this implies that the upward trend is significance and there is tendency to continue. Temperature has statistic $\mathrm{Zs}$ of 0.0309 which is less than 1.96 and implies no significance, thus the reduction may not be noticed. The auto correlation factor values ranges from 0.59 to 0.99 for all the parameters, indicating a good fit. Standard Anomaly index (SIA) results showed that trends for the temperature depicts downward trend with the slope of the trend equations are negative, this implies that temperature has tendency to decrease. Rainfall, relative humidity and sea level rise exhibited upward trend which implies tendency to increase. However, the mean wind speed exhibited upward trend while both maximum and minimum wind speed exhibited downward trend, but not noticeable. It can be inferred that both MannKendall trend test and standard anomaly index showed that there is tendency for trend increase in rainfall, humidity, windspeed and sea level rise, while temperature has tendency to decrease. This could be due to impact of climate variability which can influence flooding pattern in the coastline of Lagos State. CJASEM

http://dx.doi.org/10.4314/jasem.v20i3.34
\end{abstract}

Key Words: Climate variables, Mann-Kendall test, Standard Anomaly index, hydro-Meteorological variables, Lagos coast.

Global climate change is a sensitive subject that affects all key aspects of human existence, the socioeconomic, political and the biophysical environments that dictate the quality of life on the earth. In effect, environmentalists in the last few decades have been sounding warnings on the uncontrolled emissions of pollutants into the atmosphere, enhanced greenhouse effect, and depletion of the ozone layer which are seriously threatening the life support system on earth. Simultaneously, pristine rainforests have been cleared at a tremendous rate in the pursuit of agricultural and timber products and fuel wood. This global climate change should be regarded as one of the greatest threats to the world. The past and current trend of the hydro-meteorological variables can assist in visualization and characterization of the past, current and future water resource situation within the Lagos coastline. Reviews of related works include Inter-governmental Panel on Climate (2007), Raziel (2008), Salami et al., (2011), Mondal et al. (2012), Ojoye (2012), Ikpee (2015). From the review work a range of potential impacts of climate change and variability on the Hydrological regime for various geographic areas has been hypothesized and the Mann-Kendall on-parametric test (MKNT) and Standard Anomaly Index (SAI) was adopted to detect trends observed by most authors.

Mann-Kendall non-parametric test is widely used for the analysis of trends in meteorological and hydrological series. One of the advantages of this method is its applicability for a time series

* Corresponding author's e-mail: awsalami2009@gmail.com 
distribution, which does not follow a typical statistical distribution. This method of analysis adopts two parameters such as the Kendall statistic, $S$ and the normalized test statistic Zs which are used to determine the nature and level of the significance of trends exhibited by the variables. Generally, a positive value of $S$ is an indication of an upward trend, while a negative value indicates a downward trend. Also the value of Zs greater than 1.96 at a selected confidence limit of $95 \%$ shows that the trends can be interpreted as statistically significant or otherwise.

Standard Anomaly Index (SAI) was first used by Karus (1997) to provide a synthesis of the average area behaviour of precipitation at a specified time. The index was found to be effective for rainfall variability in the Niger Basin area (Ojo, 1991). SAI was used to test for the trend and fluctuation of hydro-meteorological parameters in the study of climate change impact on water resources and adaptation strategies in the Sudano- Sahelian Ecological Zone (SSEZ) of Nigeria (Ojoye, 2012). It is used to investigate the annual rainfall trends in homogeneous rainfall of sub-divisions of western Iran in order to assess the variability during the last thirty five years (Raziel, 2008). The SAI is used for any hydro-meteorological parameter; the name of the index is adopted to suit the parameter under consideration (Ojoye, 2012).The climate data used for this study were subjected to standardized anomaly index (SAI) in order to depict the fluctuation and trend exhibited by each of the hydro-meteorological parameters. The anomaly index for fluctuation analysis with line bar above the reference zero line means that the year has a positive (or surplus) anomaly while those with line bars below the reference zero line means negative ( or deficit) anomaly (Valt et al., 2005).

The purpose of this study is to investigate the variability of meteorological variables in the coastal area of Lagos Nigeria and to deduce the influence of variability on the meteorological variables within the coastline. In achieving this, the Mann-Kendall nonparametric test and Standard Anomaly Index (SAI) was explored to establish trends. The objectives of this study are to analyze the meteorological variables within Lagos coast using the Mann-Kendall trend analysis and Standard Anomaly Index in order to identify the nature of trend exhibited by the variables and the consequence of variability of climate change on the meteorological variables.

\section{MATERIALS AND METHODS}

Study Area: Adelekan (2009) reported that Lagos is the fifth largest city in the world and is the foremost manufacturing, port city in West Africa, and the hub of business and economic development in Nigeria. This coastal city is situated within latitudes $6^{\circ} 23^{\prime} \mathrm{N}$ and $6^{\circ} 41^{\prime} \mathrm{N}$ and longitudes $2^{\circ} 42^{\prime} \mathrm{E}$ and $3^{\circ} 42^{\prime} \mathrm{E}$ (Figure 1). The city has the largest concentration of multinationals and commercial institutions and is home to about 60 percent of Nigeria's non-oil economy. Lagos grew from 300,000 inhabitants in 1950 to 7.7 million people in 1990 . United Nations estimates indicate that by 2000 the total population for Lagos had reached 13.4 million, projecting it to reach over 20 million by 2010 (LMDGP Project Appraisal Document, 2006). The growth of Lagos is primarily the result of its location on the west coast of Africa which has fostered the development of trade within its hinterland as well as with the neighboring international state. The role of Lagos as the administrative capital of Nigeria until December 1991 also contributed to its growth. The high population growth rate of Lagos has been largely attributed to rural-urban migration which accounts for up to $75 \%$ of the population increase (Abumere, 2004). Study conducted by Adelekan (2009) revealed that Lagos had an area of about $200 \mathrm{~km}^{2}$ in 1960 and by the beginning of the $21^{\text {st }}$ century the contiguously built-up area of Lagos was estimated to be about $1,140 \mathrm{~km}^{2}$. For sections of the metropolis along the coastline large areas have been built-up with high population densities. Except for Eti - Osa local government area, the newly developing area of Lagos expansion, which presently has $43.45 \%$ of its total area built-up, other local government areas with coastlines have over $50 \%$ of their total area built-up. Shomolu local government has the most artificial land cover of about $90 \%$. Much urban development has taken place in Eti-Osa local government area especially since 1983 when the Lagos state government began to allocate the Lekki Peninsula for urban development. Along with the planned development of this peninsular is the emergence of fast growing poor urban neighborhoods around existing rural settlements. This emerging development pattern has implications as the development of the Lekki Peninsular is with little or no consideration for sea level rise. This makes this rapidly urbanizing area and the growing population vulnerable to sea level rise and climate change.

Nigeria has a coastline of about $850 \mathrm{~km}$, from the western border with the Benin Republic to the eastern border with the Republic of Cameroon. Geomorphologically, the Nigerian coast is divided into four main units: the Barrier Lagoon coast, the 
Mud coast, the Niger Delta and the Strand coast (Nwilo, 1995 and Nwilo \& Onuoha, 1993). The Barrier Lagoon coast of Nigeria is part of a series of Barrier Lagoon coasts along the West African coast starting from Cote d'Ivoire and ending in Nigeria. Within Nigeria, it is made up of a number of islands, lagoons and creeks including Lagos Island, Ikoyi Island, Victoria Island, Lekki, the Lekki and Lagos Lagoons, Badagry and Badagry Creeks. One common feature of the islands is that they are low lying. In Lagos and Victoria islands for example, heights of 1.5-4.0 $\mathrm{m}$ a.m.s.l. are very common. This is despite the fact that these islands were sand filled. In addition to the low topography of these barrier islands, some of them such as Ikoyi, Lagos, Victoria Island and Lekki are either fully or partially developed commercial and residential areas and could be said to constitute the most important commercial and residential parts of the country (Nwilo \& Onuoha, 1993).

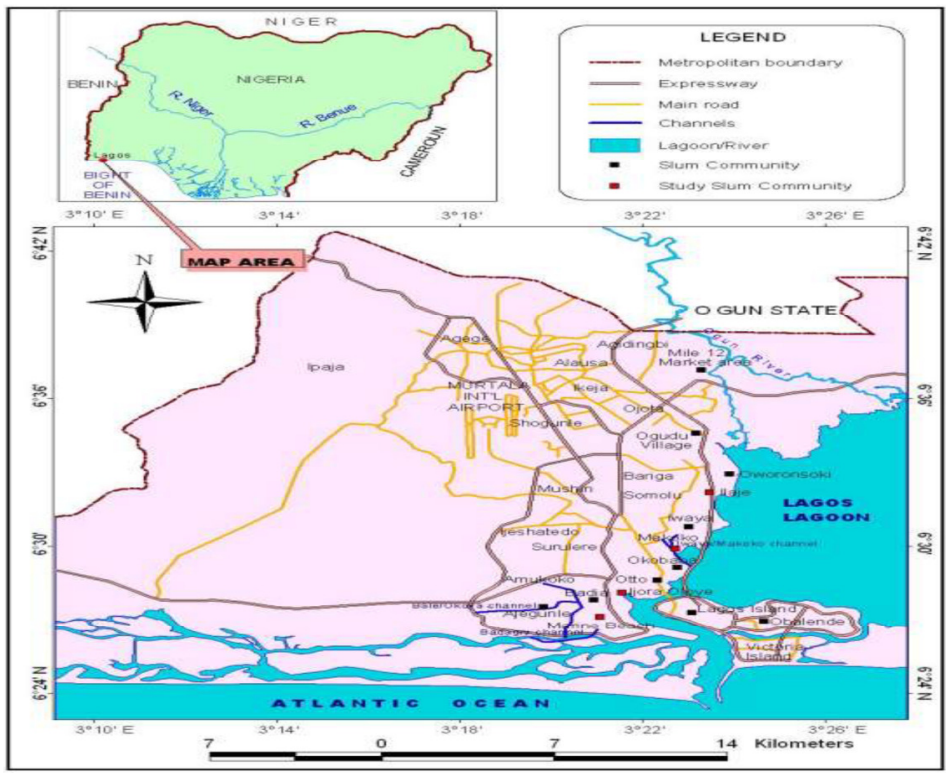

Fig 1 Lagos Coastal Slum Communities (Adapted from Gandy, 2005)

Data Collection: The data required for this study are the meteorological variables which include rainfall, sea rise level, air temperature, relative humidity and wind speed which were all obtained from the Nigeria
Meteorological Agency (NIMET) Oshodi, Lagos. The sampling station for this study is the Victoria Island marine station. The details of meteorological variables and years of record is presented in Table 1

Table 1: Victoria Island Marine Station with meteorological Parameters with Years

\begin{tabular}{lcl}
\hline S/No & Meteorological Parameters & Years of Record \\
\hline Air temperature & $1992-2012$ & \\
Rainfall & $1992-2012$ & \\
Relative Humidity & $1992-2012$ & \\
Wind Speed & $1992-2012$ & \\
Sea level rise1992 & -2012 & \\
\hline
\end{tabular}

Source: Nigeria Meteorological Agency (NIMET) Oshodi, Lagos

Data Analysis: The Mann-Kendall non-parametric test was adopted in identifying trends in time series data. It compares the relative magnitudes of sample data rather than the data values. The major benefit of this test is that the data need not conform to any particular distribution. Moreover data reported as non-detects can be included by assigning them a common value that is smaller than the smallest measured value in the data set. The procedure for the trend analysis assumes that there exists only one data value per time period. When multiple data points exist for a single time period the median value is used. The data values are evaluated as an ordered time series and each data value is compared to all subsequent data values. The initial value of the Mann-Kendall statistic (S) is assumed to be 0 , if there is no trend. If a data value from a later period is higher than a data value from an earlier time period, 
then $S$ is incremented by 1 . Conversely, if the data value from a later period is lower than a data value sampled earlier, then $\mathrm{S}$ is decremented by 1 . The net result of all the increments and decrements yield the final value of $\mathrm{S}$. The expressions for the MannKendall trend analysis are given in Equations 1 to 4. Let $X_{1}, X_{2} . X_{n}$ represents $n$ data points where $X_{j}$ represents the data point at time $\mathrm{j}$. Then the MannKendall statistic (S) is given (Hirsch et al., 1982 and Gan, 1992) in Equations (1) and (2). A very high positive value of $\mathrm{S}$ is an indication of an increasing trend while a very low, negative value indicates a decreasing trend. However, it is important to compute the probability associated with $\mathrm{S}$ and the sample size $\mathrm{n}$ in order to statistically quantify the significance of the trend (Prashanth, 2005). Calculation of the variance of $S$, is given by using Equation (3) where $n$ is the number of data points, $g$ is the number of tied groups (a tied group is a set of sample data having the same value) and tpis the number of data points in the pth group. Computation of a normalized test statistic $\mathrm{Z}$ is shown in Equation (4).

$$
\begin{aligned}
& S=\sum_{k=1}^{n-1} \sum_{j=k+1}^{n} \operatorname{sgn}\left(x_{j}-x_{k}\right), \\
& \operatorname{sgn}\left(x_{j}-x_{k}\right)= \begin{cases}1 & \text { if } x_{j}-x_{k}>0 \\
0 & \text { if } x_{j}-x_{k}=0 \\
-1 & \text { if } x_{j}-x_{k}<0\end{cases} \\
& V A R(S)=\frac{1}{18[n-1)(2 n+5)-\sum_{p=1}^{q} t_{p}\left(t_{p}-1\right)\left(2 t_{p}+5\right)} \\
& Z=\left\{\begin{array}{ll}
\frac{S-1}{\sqrt{V A R(S)}} & \text { if } S>0 \\
\frac{S A R(S)}{\sqrt{V+1}} & \text { if } S<0
\end{array}\right]
\end{aligned}
$$

The test statistic $\mathbf{Z}_{\mathbf{s}}$ is used as a measure of trend significance. In fact this analysis is used totest the null hypothesis, H0: There is no monotonic trend in the data if $|\mathbf{Z s}|$ is greater than $Z_{\alpha / 2}$ where $\propto$ represents the chosen significance level (usually $5 \%$ with $Z_{0.025}=1.96$ ) then the null hypothesis is invalid, meaning that the trend is significant. Being significant implies that the trend has a causative factor and did not occur by chance. The MannKendall statistical analysis has been found to be an excellent tool for trend detection in different applications
(Prashanth, 2005) The Mann-Kendall non-parametric test was appliedto the meteorological variables in the coastal area of Lagos state (Ikpee, 2015)

Standardized anomaly index (SAI) is a statistical tool used to depict the fluctuation exhibited by the hydrometeorological parameters. SAI was first used by Karus (1997) to provide a synthesis of the average area behaviour of precipitation at a specified time. The index was found to be effective for rainfall variability in the Niger Basin area (Ojo, 1991). SAI was used to test for the trend and fluctuation of hydro-meteorological parameters in the study of climate change impact on water resources and adaptation strategies in the Sudano- Sahelian Ecological Zone (SSEZ) of Nigeria (Ojoye, 2012). It 
is used to investigate the annual rainfall trends in homogeneous rainfall of sub-divisions of western Iran in order to assess the variability during the last thirty five years (Raziel, 2008). The SAI is used for any meteorological parameter; the name of the index is adopted to suit the parameter under consideration (Ojoye, 2012; Ikpee, 2015).The climate data used for this study were subjected to standardized anomaly index (SAI) in order to depict the fluctuation and trend exhibited by each of the meteorological parameters. The anomaly index for fluctuation analysis with line bar above the reference zero line implies that the year has a positive (or surplus) anomaly while those with line bars below the reference zero line means negative ( or deficit) anomaly (Valt et al., 2005). The equation adopted is presented in equation (5).

$$
X_{T M}=\frac{1}{N} \sum_{i=1}^{N}\left(X_{T}-X_{M}\right) \sigma
$$

Where: $\mathrm{X}_{\mathrm{TM}}=$ variable departure for the next year, $\mathrm{X}_{\mathrm{T}}=$ the year variable totals, $\mathrm{X}_{\mathrm{M}}=$ the mean variable for the base period, $\sigma=$ standard deviation for the base period, $\mathrm{N}=$ number of years when the data are available.

\section{RESULTS AND DISCUSSION}

Mann-Kendall: The Mann-Kendall analyses were carried out for the annual parameters and the outcome are presented in Tables $2-4$ for mean, maximum and minimum respectively

Table 2: Mann-Kendall results for Mean Annual data at Victoria Island Marine Station

\begin{tabular}{llllll}
\hline Variable & $\begin{array}{l}\text { Auto correlation } \\
\text { factors }\end{array}$ & Kendall S & Zs & Trend Nature & $\begin{array}{l}\text { Trend } \\
\text { Significance }\end{array}$ \\
\hline Temperature & 0.993 & -2 & 0.0309 & Negative & No \\
Rainfall & 0.837 & 55 & 1.9668 & Positive & Yes \\
Relative Humidity & 0.719 & 101 & 3.0895 & Positive & Yes \\
Wind Speed & 0.787 & 74 & 2.2553 & Positive & Yes \\
Sea level rise & 0.653 & 130 & 3.9855 & Positive & Yes \\
\hline
\end{tabular}

All the mean meteorological parameters such as rainfall, relative humidity, wind speed and sea level rise exhibited positive Kendall's (S) values which indicate that all the parameters have positive trend and can increase over time, however temperature showed negative Kendall's (S). Tidal rise, rainfall, relative humidity and wind speed has statistics $\mathrm{Zs}$ as $3.9855,1.9668,3.0895$ and 2.2553 respectively which are more than 1.96 (test statistics for a significant level of $5 \%$ i.e $\left(Z_{0.025}=1.96\right)$, this shows how the parameters have displayed positive statistical significance and this trend is likely to continue. Temperature has statistic Zs as 0.0309 which is less 1.96 hence there is no statistics significance. The auto correlation factor range of $0.653-0.993$ for all the parameters showed a good fit for the analysis as presented in Table 2 .

Table 3: Mann-Kendall results for Minimum Annual data at Victoria Island Marine Station

\begin{tabular}{llllll}
\hline Variable & $\begin{array}{l}\text { Auto correlation } \\
\text { factors }\end{array}$ & Kendall S & Zs & Trend Nature & $\begin{array}{l}\text { Trend } \\
\text { Significance }\end{array}$ \\
\hline Temperature & 0.847 & 51 & 1.5448 & Positive & No \\
Rainfall & 0.888 & 37 & 1.1122 & Positive & No \\
Relative Humidity & 0.724 & 97 & 2.9659 & Positive & Yes \\
Wind Speed & 0.839 & 54 & 2.9659 & Positive & No \\
Sea level rise & 0.651 & 125 & 3.8310 & Positive & Yes \\
\hline
\end{tabular}

Table 3 showed that all the maximum values of the parameters except temperature exhibited a positive trend as shown by Kendall's (S). The statistics Zs for sea level rise and relative humidity are 3.6456 and
2.3171 respectively showing that the trend is significant, while the positive trend exhibited by temperature, rainfall and wind speed is not significant

Table 4: Mann-Kendall results for Maximum Annual data at Victoria Island Marine Station

\begin{tabular}{llllll}
\hline Variable & $\begin{array}{l}\text { Auto correlation } \\
\text { factors }\end{array}$ & Kendall S & Zs & Trend Nature & $\begin{array}{l}\text { Trend } \\
\text { Significance }\end{array}$ \\
\hline Temperature & 0.907 & -2 & 0.8960 & Negative & No \\
Rainfall & 0.837 & 55 & 1.6683 & Positive & No \\
Relative Humidity & 0.775 & 76 & 2.3171 & Positive & Yes \\
Wind Speed & 0.870 & 43 & 1.2976 & Positive & No \\
Sea level rise & 0.674 & 119 & 3.6456 & Positive & Yes \\
\hline
\end{tabular}


Table 4 showed that all the minimum values of the parameters exhibited a positive trend as shown by Kendall's (S). The statistics Zs for sea level rise and relative humidity are 3.8310 and 2.9659 respectively indicating that the trend is significant, while temperature, rainfall and wind speed have statistics (Zs) values less than 1.96 which implies no significance in their trend.
Standardized Anomaly Index (SAI): The air temperature, rainfall, relative humidity, wind speed and Sealevel rise at Victoria Island marine station were subjected to Standardized Anomaly Index (SAI) in accordance to equation 5. The (SAI) values obtained are plotted against the year for each station and presented in Figures 2-16, while the trend equations obtained are presented in Table 5.

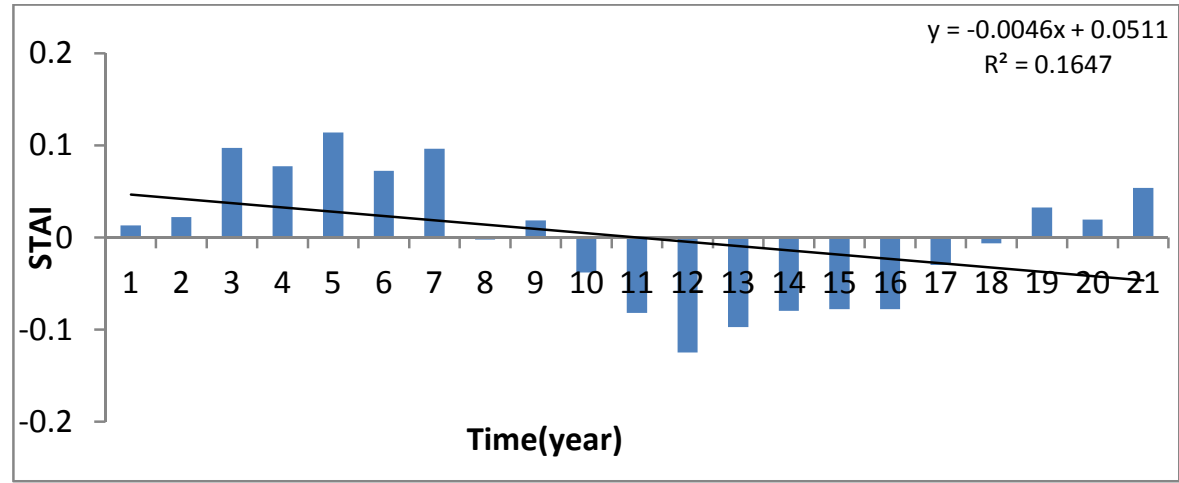

Fig 2: Mean Temperature Trend

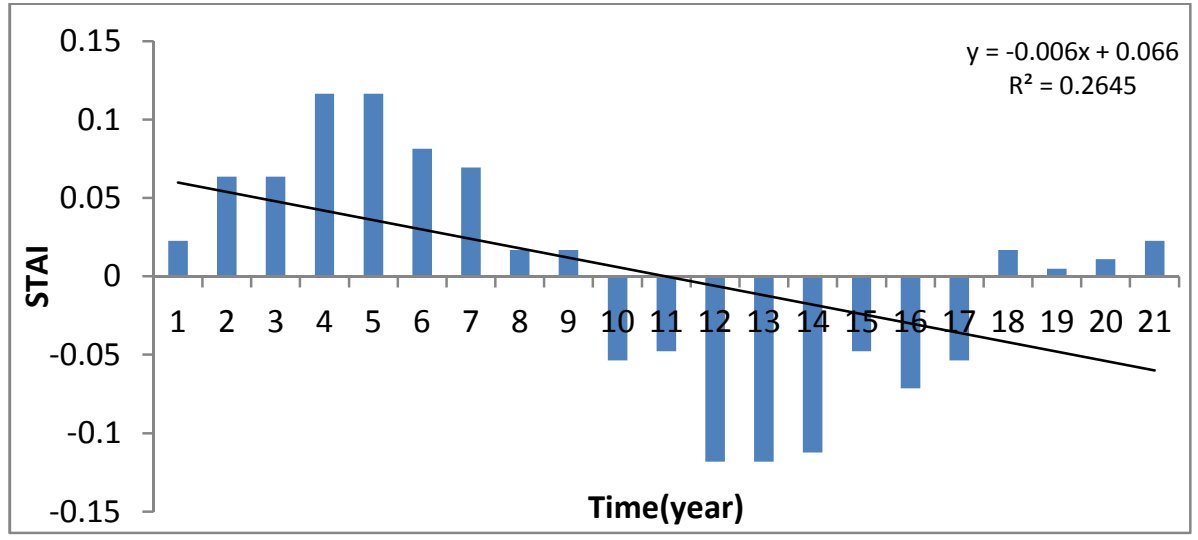

Fig 3: Maximum Temperature Trend

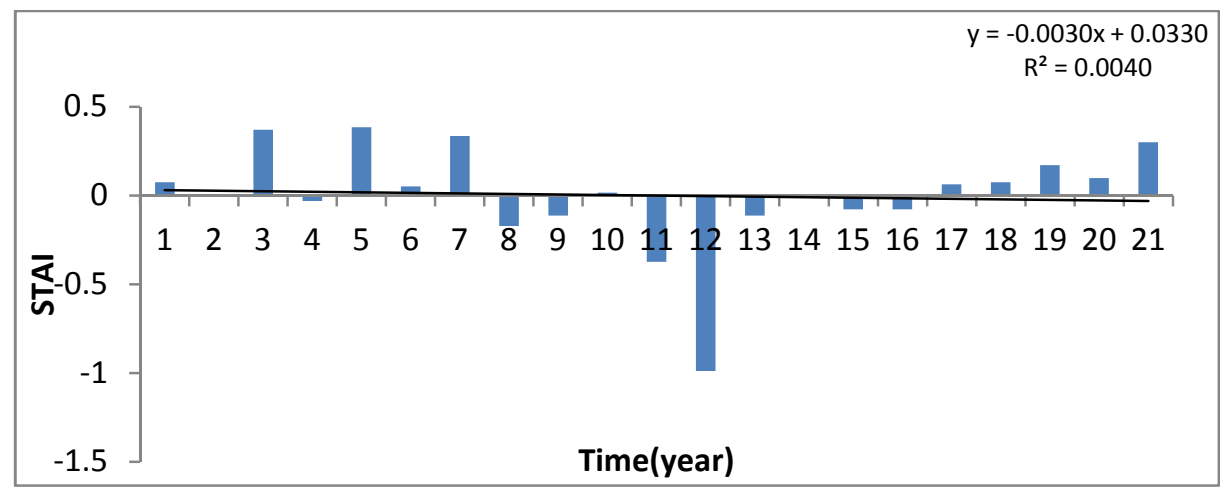

Fig 4Minimum Temperature Trend

Figure 2-3 presents the trend for the mean, minimum and maximum for temperature respectively. The parameter depicts negative trend with coefficient of determination $\left(\mathrm{R}^{2}\right)$ of $0.1647,0.0042$ and 0.2645 
respectively. It can be observed that the slope of the temperature has tendency to decrease. trend equations are negative, this implies that

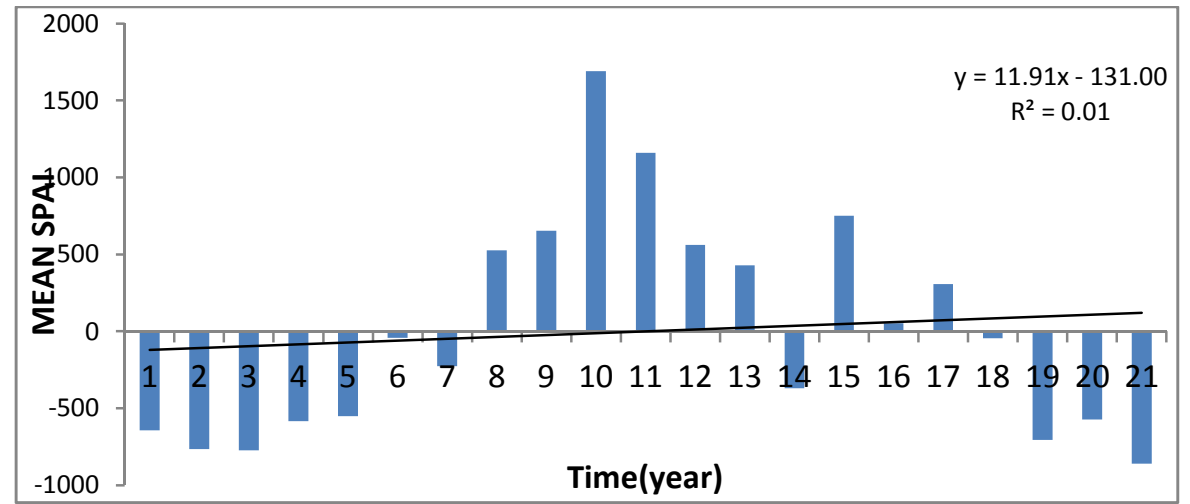

Fig5 Mean rainfalls Trend

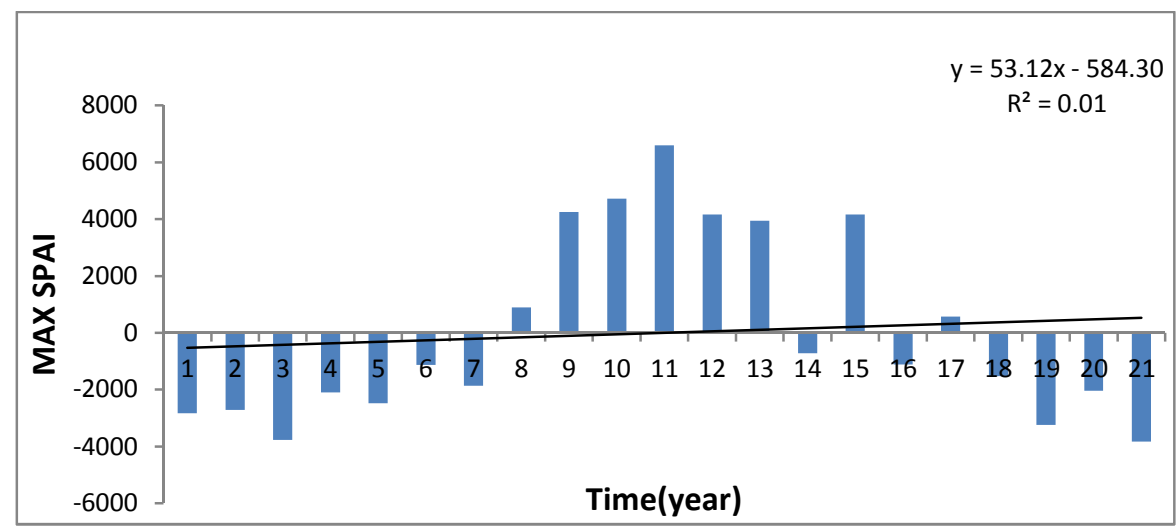

Fig6: Maximum rainfall Trend

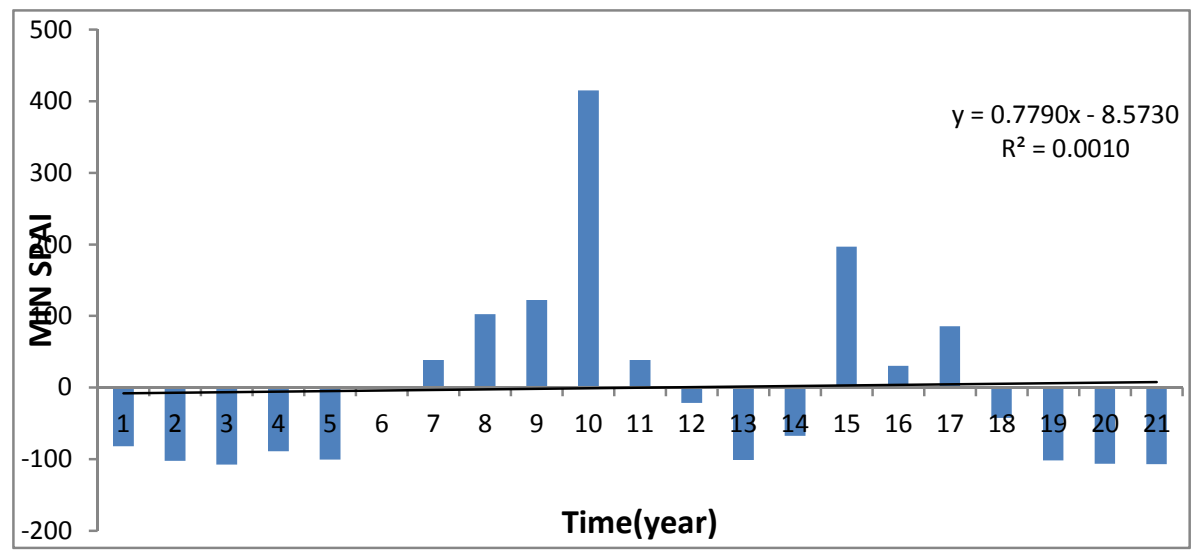

Fig 7 Minimum rainfall Trend

Figure $5-7$ showed the mean, minimum and maximum rainfall trend respectively. The parameter depicts positive trend with coefficient of determination $\left(\mathrm{R}^{2}\right)$ of $0.0109,0.0014$ and 0.0102 respectively. It can be observed that the slope of the trend equations are positive, this implies that precipitation has tendency to increase. 


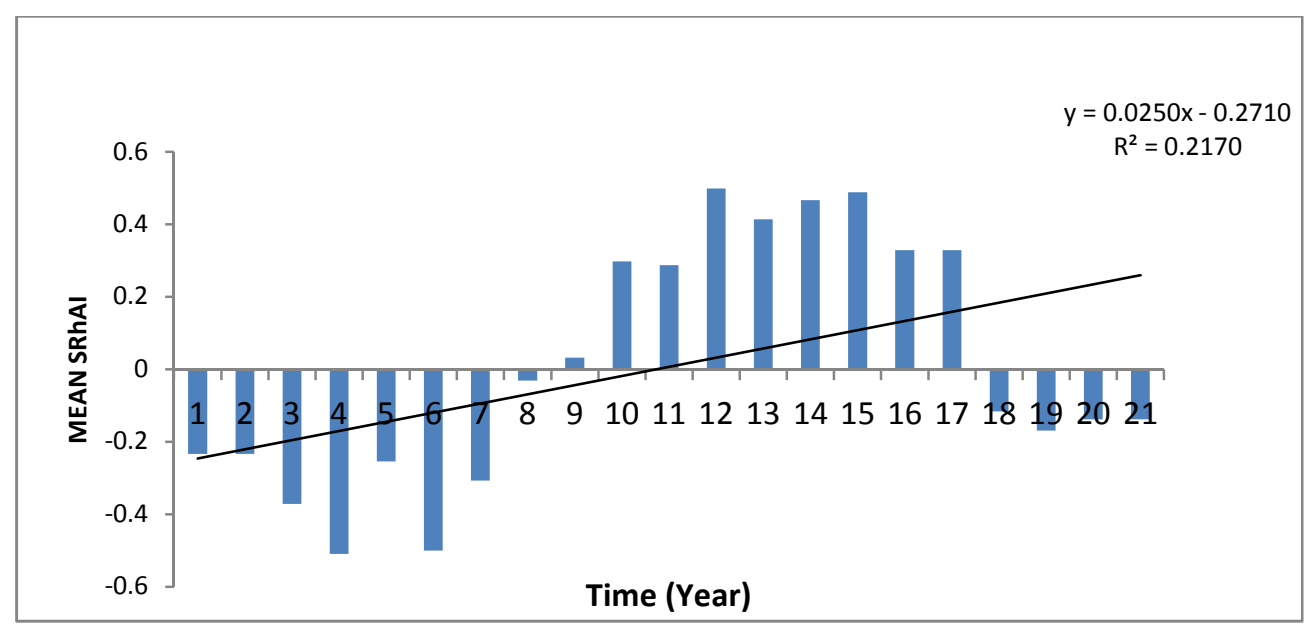

Fig8: Mean Relative humidity Trend

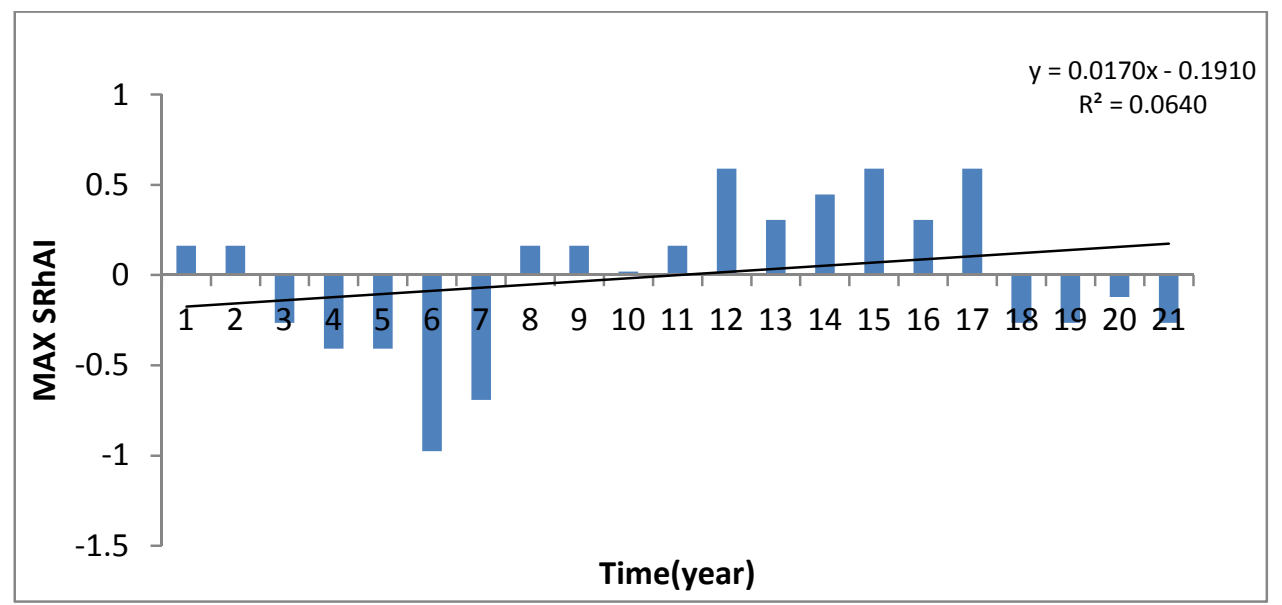

Fig 9: Maximum Relative humidity Trend

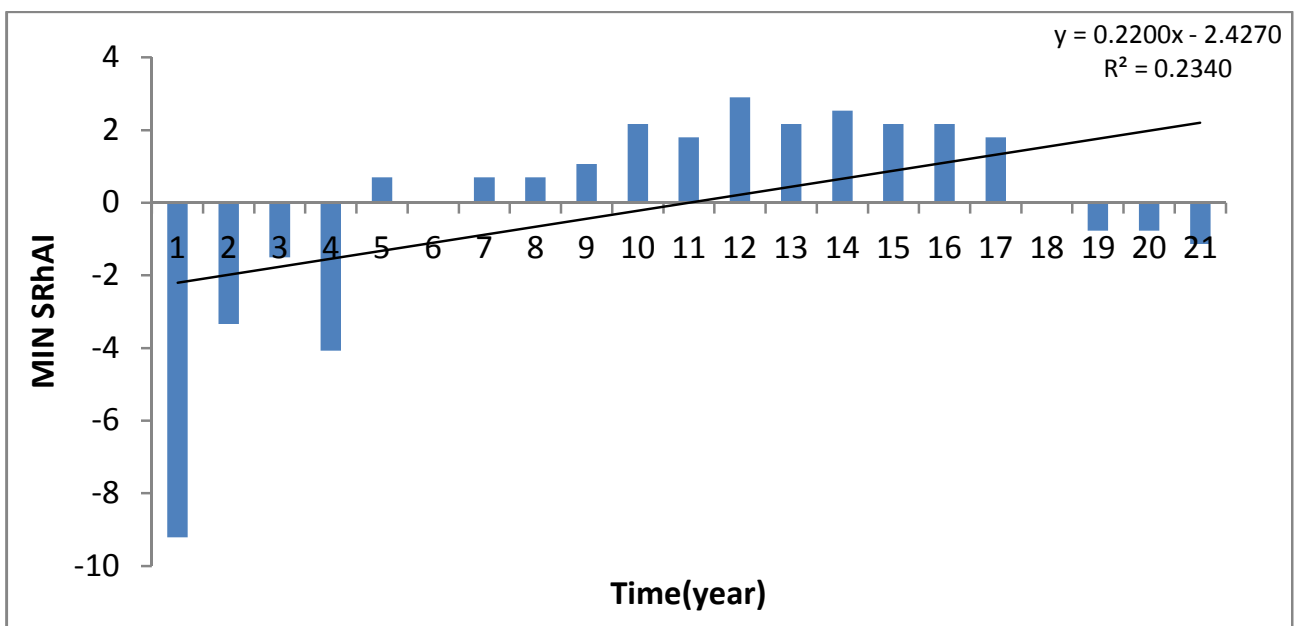

Fig10: Minimum Relative humidity Trend

Figure $8-10$ presents the trend of mean, minimum and maximum relative humidity. The parameter indicated positive trend with the coefficient of determination $\left(\mathrm{R}^{2}\right)$ of $0.2177,0.2944$ and 0.0643 respectively. It can be observed that the slope of the trend equations are positive, this implies that relative humidity has tendency to increase 


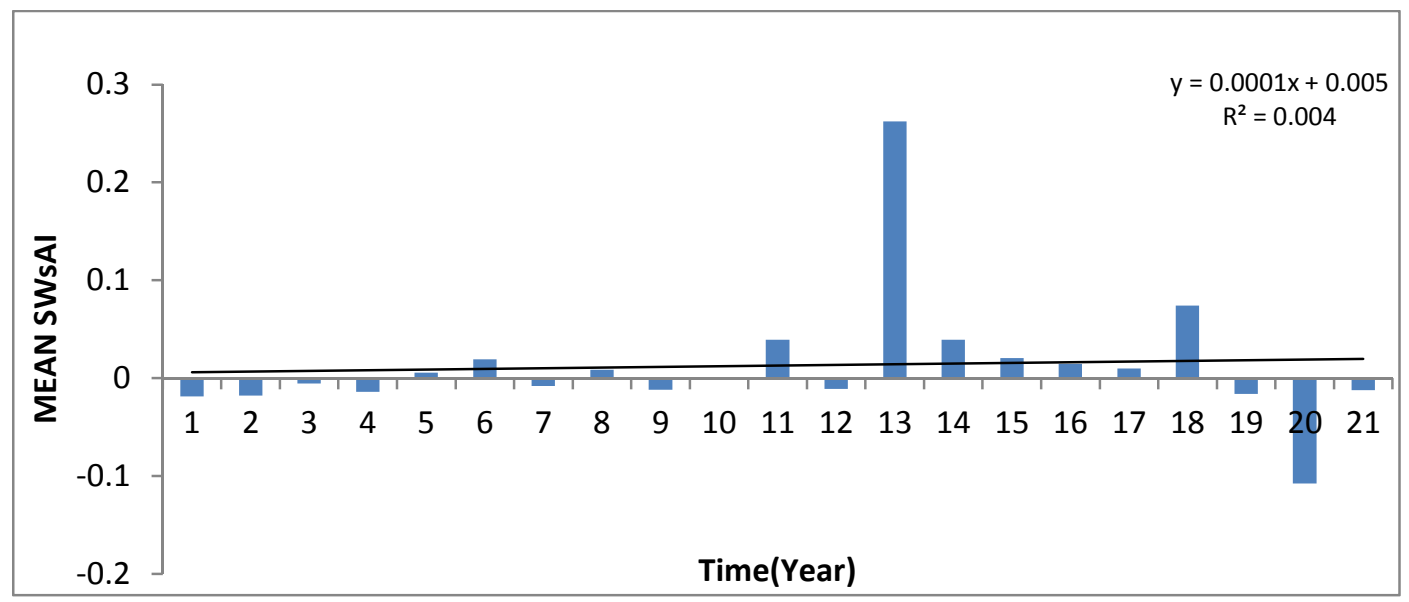

Fig11Mean Wind speed Trend

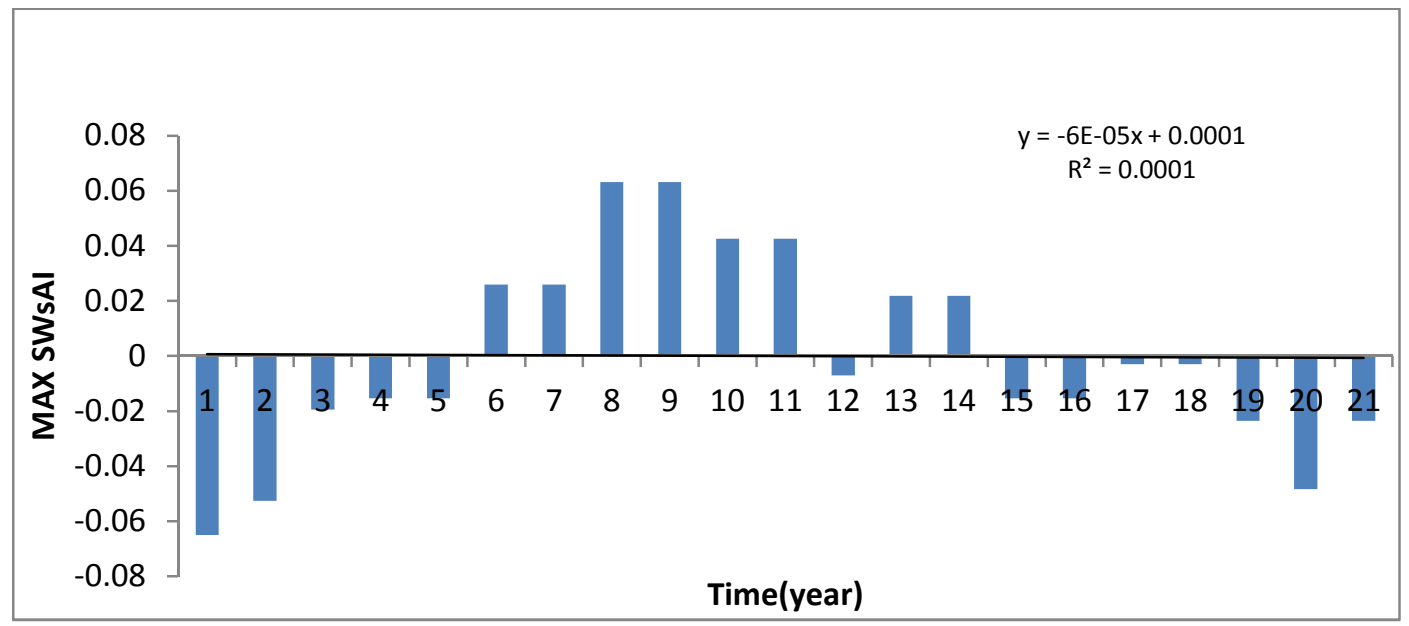

Fig12 Maximum Wind speed Trend

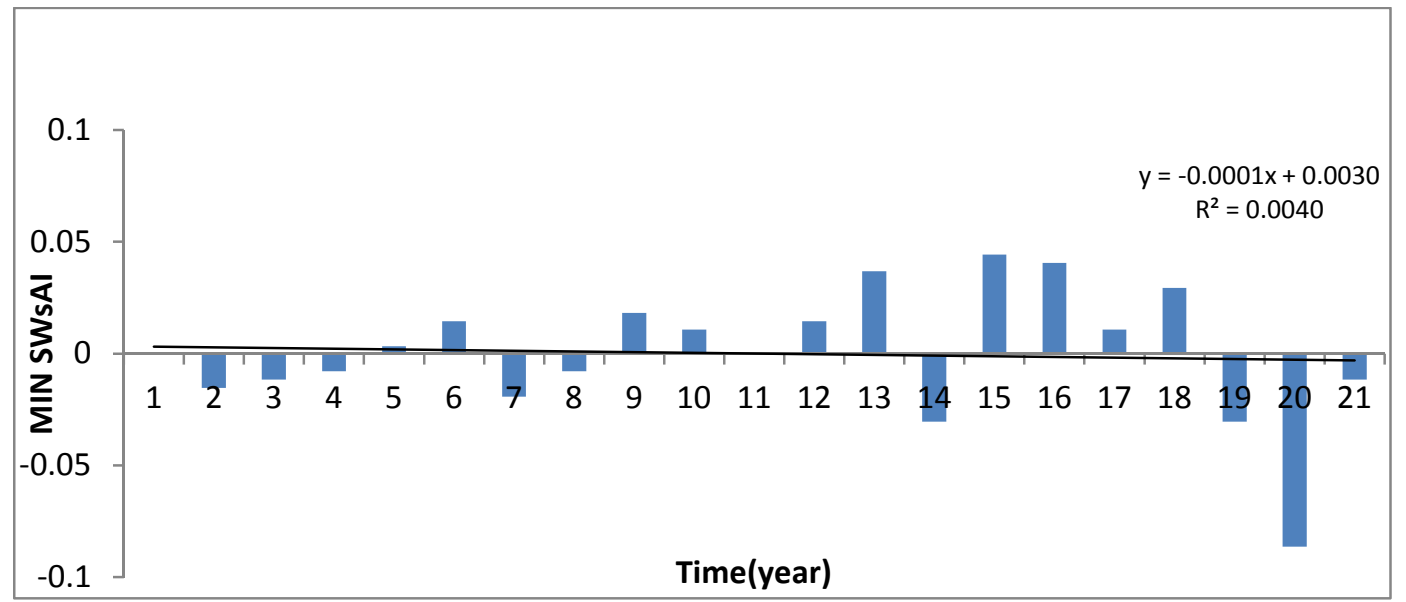

Fig 13 Minimum Wind speed Trend

Figure $11-13$ presents the trend of the mean, maximum and minimum wind speeds respectively.The mean values for the wind speed shows positive trend, while minimum and maximum values showednegative trend. The coefficient of determination $\left(\mathrm{R}^{2}\right)$ for the mean, minimum and maximum value is $0.0042,0.0042$ and 0.0001 respectively. It can be observed that the slope of the 
trend equation for the mean wind speed is positive, while the slopes of the trend equations for the minimum and maximum wind speed are negative.
This implies that wind speed has tendency to increase but may not be noticed

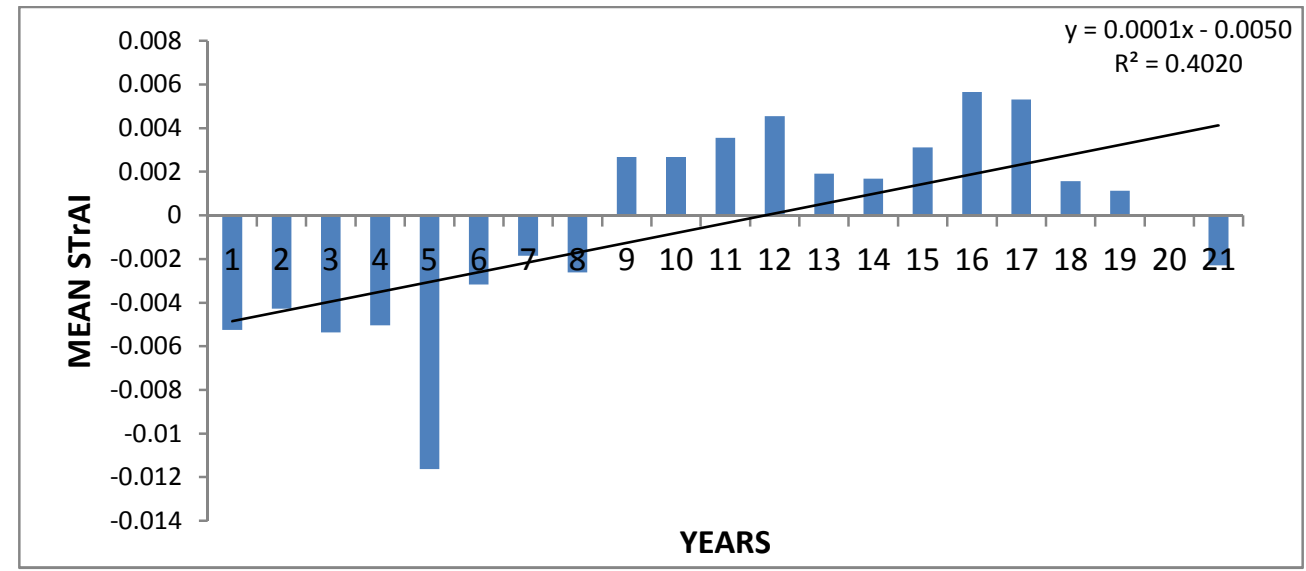

Fig 14: Mean Sea level Trend

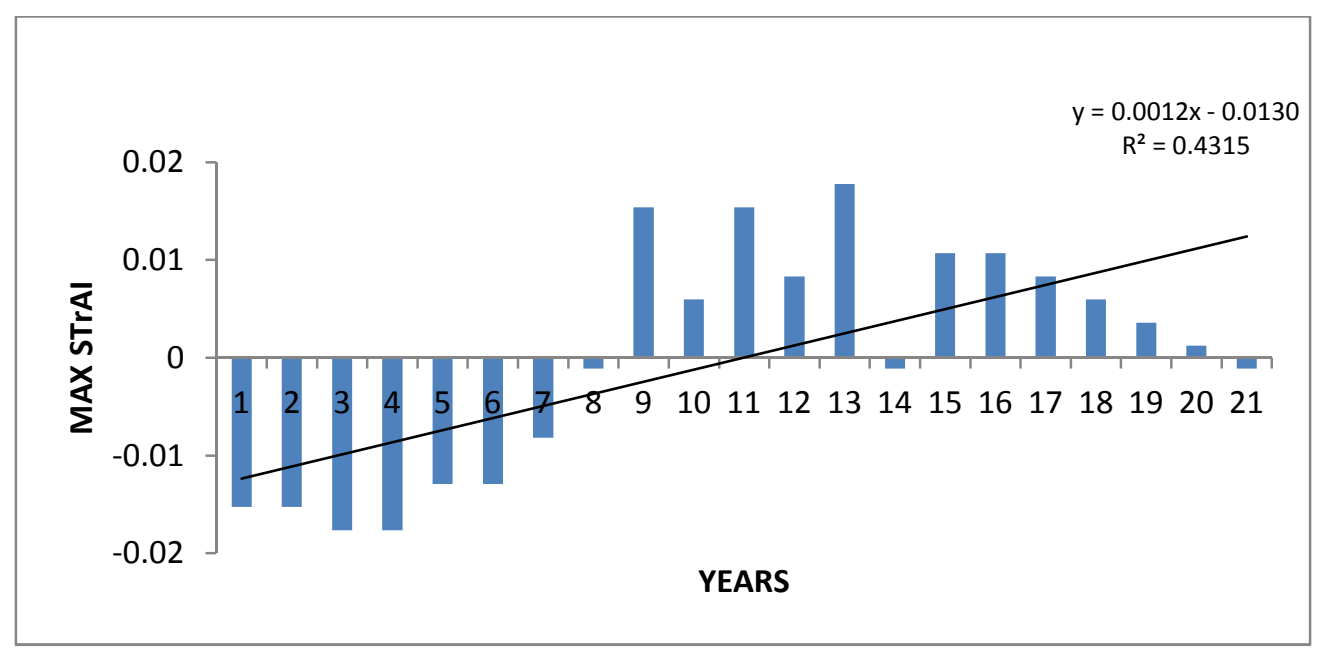

Fig 15 Maximum Sea level rise Trend

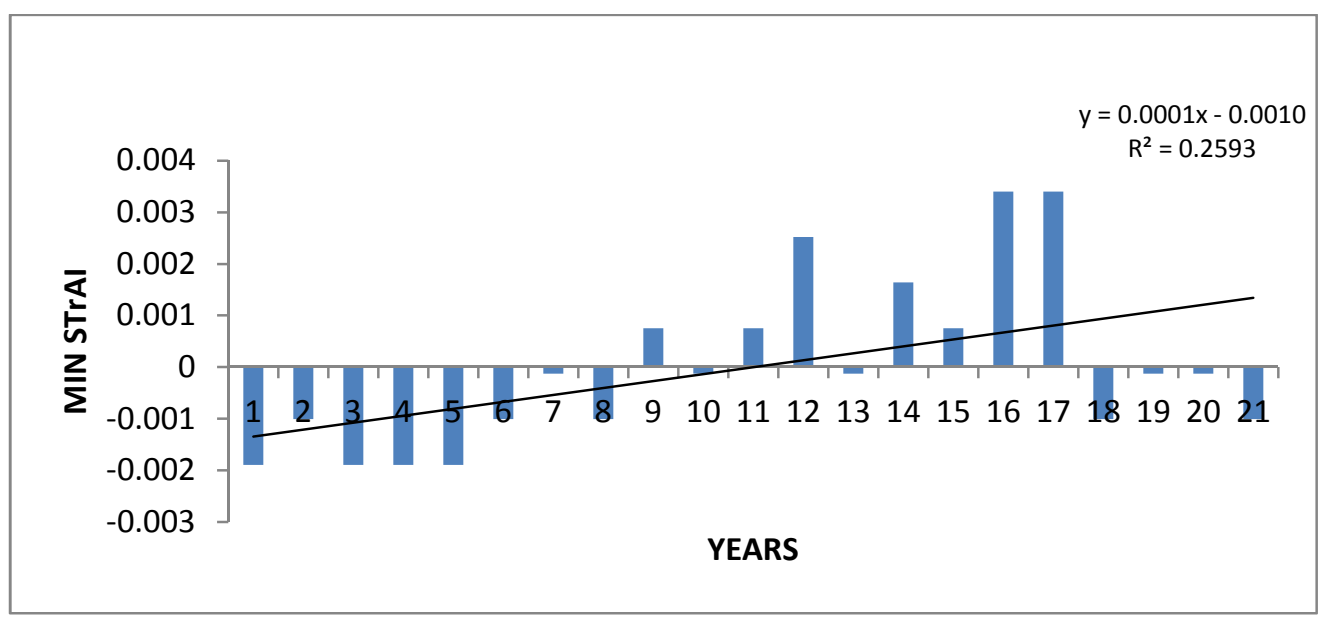

Fig 16 Minimum Sea level rise Trend 
Figures 14 - 16 present the mean, minimum and maximum of sea level rise. The parameterdepictedpositive trend with the coefficient of determination $\left(\mathrm{R}^{2}\right)$ of $0.402,2593$ and 0.4315 respectively. It can be observed that the slope of the trend equations are positive, this implies that sea level rise has tendency to increase.

The trend equations and the coefficient of determination $\left(\mathrm{R}^{2}\right)$ obtained for temperature, rainfall, relative humidity; wind speed and sealevel are presented in Table 5.

Table 5: Trend equations and coefficient of determination $\left(\mathrm{R}^{2}\right)$ for parameters

\begin{tabular}{llll}
\hline Parameters & Mean & Minimum & Maximum \\
\hline Temperature & $\mathrm{Y}=-0.004 \mathrm{x}+0.051$ & $\mathrm{Y}=-0.003 \mathrm{x}+0.033$ & $\mathrm{Y}=-0.006 \mathrm{x}+0.066$ \\
$\left({ }^{\circ} \mathrm{C}\right)$ & $\mathrm{R}^{2}=0.164$ & $\mathrm{R}^{2}=0.004$ & $\mathrm{R}^{2}=0.264$ \\
Rainfall $(\mathrm{mm})$ & $\mathrm{Y}=11.91 \mathrm{x}-131.00$ & $\mathrm{Y}=0.779 \mathrm{x}-8.573$ & $\mathrm{Y}=53.12 \mathrm{x}-584.3$ \\
& $\mathrm{R}^{2}=0.010$ & $\mathrm{R}^{2}=0.001$ & $\mathrm{R}^{2}=0.010$ \\
Relative & $\mathrm{Y}=0.025 \mathrm{x}-0.271$ & $\mathrm{Y}=0.220 \mathrm{x}-2.427$ & $\mathrm{Y}=0.017 \mathrm{x}-0.191$ \\
Humidity $(\%)$ & $\mathrm{R}^{2}=0.217$ & $\mathrm{R}^{2}=0.234$ & $\mathrm{R}^{2}=0.064$ \\
Wind Speed & $\mathrm{Y}=0.0001 \mathrm{x}-0.005$ & $\mathrm{Y}=-0.0001 \mathrm{x}-0.003$ & $\mathrm{Y}=-0.00006 \mathrm{x}-0.0001$ \\
$(\mathrm{~m} / \mathrm{s})$ & $\mathrm{R}^{2}=0.004$ & $\mathrm{R}^{2}=0.004$ & $\mathrm{R}^{2}=0.0001$ \\
Sea levelrise & $\mathrm{Y}=0.0001 \mathrm{x}-0.005$ & $\mathrm{Y}=0.0001 \mathrm{x}-0.001$ & $\mathrm{Y}=0.0012 \mathrm{x}-0.013$ \\
$(\mathrm{~m})$ & $\mathrm{R}^{2}=0.402$ & $\mathrm{R}^{2}=0.2593$ & $\mathrm{R}^{2}=0.4315$ \\
\hline
\end{tabular}

Table 5 present the trend equations and the coefficient of determination $\left(\mathrm{R}^{2}\right)$ between the parameters and period. It can be observed that the coefficient of determination $\left(\mathrm{R}^{2}\right)$ for all the parameters are generally low, which indicated poor correlation between the parameters and time. However, the trend pattern revealed the nature of the parameters in relation with time, which is either increasing or decreasing.

Conclusion: It can be inferred from both MannKendall trend test and standard anomaly index that there is tendency for increments in rainfall, relative humidity, windspeed and sealevel rise, while reduction in temperature. This could be due to impact of climate change on the parameters thus there is needto monitor the variability of the hydrometeorological variables in order to alleviate the incessant flooding problem of the coastline of Lagos state.

Acknowledgments: The authors would like to thank the management of Nigeria Meteorological Agency (NIMET) Oshodi, Lagos for providing the meteorological data needed for this study. The authors would also thank the management and staff of the Department of Water Resources and Environmental Engineering, University of Ilorin, Ilorin, Nigeria for their technical support.

\section{REFERENCE}

Adelekan, I.O (2009). Vulnerability of poor urban Coastal Communities to Climate Change in Lagos, Nigeria. Paper presented at the fifth Urban Research Symposium.
Abumere, S.I. (2004). The State of Lagos Mega City and other Nigerian Cities. Ministry of Economic Planning and Budget, Lagos

Gan, T.Y., (1992). Finding Trends in Air Temperature and Precipitation for Canada and Northeastern United States. In: Kite, G.W., Harvey, K.D. (Eds). Using Hydrometric Data toDetect and Monitor Climate Change, Proceedings of NHRI Workshop No. 8 National Hydrology Research Institute, Saskatoon, S.K, pp. $57-78$

Gandy, M. (2005) "Learning from Lagos" New Left Review 33, pp 36-52.

Hirsch, R.M., Slack, J.R., Smith, R.A., (1982). Techniques of Trend Analysis for Monthly WaterQuality Data,Water Resources Research, Volume 18, pp. 107-121

Ikpee, D. O. (2015) Evaluation of impact of climate change on the coastal area of Lagos state using Statistical and Artificial Neural Network methods. M.Eng Thesis, Civil Engineering Department, university of Ilorin, Ilorin, Nigeria

IPCC (2007) Intergovernmental Panel on Climate (IPCC) 2007, Climate Change

Kraus, E.B (1997) Subtropical droughts and crossequatorial energy transports Mon. Wea. Rev.105: 1009-1018.

LMDGP (2006), Main Report Lagos State Urban Upgrading Project Confirmation Survey, Lagos Metropolitan Development and Governance

*Corresponding author's e-mail: awsalami2009@gmail.com 
Project (LMDGP), Report written by O. Soyombo.

Mondal, A., SanandaKundu, S., Mukhopadhyay, A., (2012). Rainfall Trend Analysis by MannKendall Test: A Case Study of North-Eastern Part of Cuttack District, Orissa. InternationalJournal of Geology, Earth and Environmental Sciences, Volume 2(1), pp. 70-78

Nwilo, P. C. \&Onuoha, A. (1993) Environmental impacts of human activities on the coastal areas of Nigeria, In: Coastlines of Western Africa (ed. by L. F. Awosika\& O. Magoon). American Society of Engineers

Ojo O (1991). "Overcoming hunger: The challenges in meteorological hazards Ekuwem E. E. (Eds), Meteorological hazards and development, Kola Okanlawom Press, Lagos, pp. 22-36

Ojoye, S. (2012) Climate Change Impact on Water Resources and Adaptation Strategies in the Sudano-Sahelian Ecological Zone of Nigeria. A Ph.D Thesis, Department of Geography and Environmental Management, University of Ilorin, Ilorin, Nigeria.
Prashanth, K.,( 2005). Mann-Kendall Analysis for the Fort Ord Site, 1155,HydroGeoLogic, Inc. Annual Groundwater Monitoring Report, California.U.S, Army Corps of Engineers.1-7

Raziel, T. (2008), Investigation of Annual precipitation Trends in Homogeneous precipitationSub-Divisions of western Iran. BALWOIS Ohrid, Macedonia Republic pp, 1-7.

Salami, A.W., Olofintoye, O.O., Sule, B.F., (2011). Modeling Global Warming Impact on theRainfall of Some Selected Cities in the Niger Delta of Nigeria,Journal of Engineering Research (JER), Volume 16(2), pp. 1-12

Valt, M., Cagnati, A., Crepaz, A. and Marigo, G. (2005) Snow precipitation in the Last years onItalian ALPS, PP. $654-657$. 